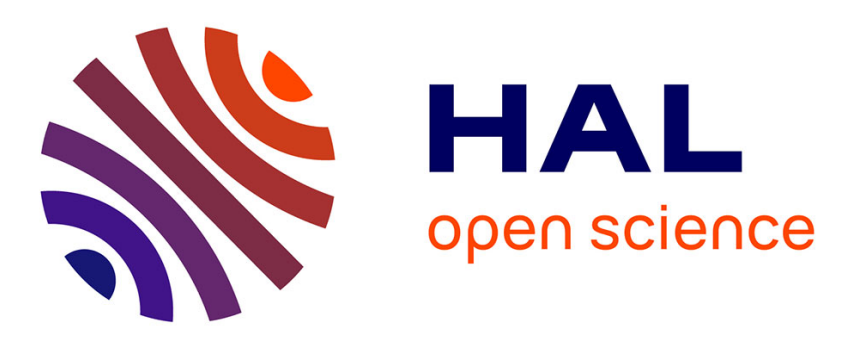

\title{
Building world narratives for climate change impact, adaptation and vulnerability analyses
}

Stéphane Hallegatte, Przyluski Valentin, Adrien Vogt-Schilb

\section{To cite this version:}

Stéphane Hallegatte, Przyluski Valentin, Adrien Vogt-Schilb. Building world narratives for climate change impact, adaptation and vulnerability analyses. Nature Climate Change, 2011, 1 (3), pp.151155. 10.1038/nclimate1135 . hal-00618688

\section{HAL Id: hal-00618688 \\ https://hal-enpc.archives-ouvertes.fr/hal-00618688}

Submitted on 2 Dec 2011

HAL is a multi-disciplinary open access archive for the deposit and dissemination of scientific research documents, whether they are published or not. The documents may come from teaching and research institutions in France or abroad, or from public or private research centers.
L'archive ouverte pluridisciplinaire HAL, est destinée au dépôt et à la diffusion de documents scientifiques de niveau recherche, publiés ou non, émanant des établissements d'enseignement et de recherche français ou étrangers, des laboratoires publics ou privés. 


\title{
Building world narratives for climate change impact, adaptation and vulnerability analyses
}

\author{
Stephane Hallegatte ${ }^{1,2}$, Valentin Przyluski ${ }^{1}$, Adrien Vogt-Schilb ${ }^{1}$ \\ ${ }^{1}$ Centre International de Recherche sur l'Environnement et le Développement, CIRED, ENPC \\ ${ }^{2}$ Ecole Nationale de la Météorologie, Météo-France \\ Contact: hallegatte@centre-cired.fr
}

The impacts of climate change on human systems depend not only on the level of emissions but also on how inherently vulnerable these systems are to the changing climate. There are large uncertainties on the future degrees of development and structure of societies and economies and hence the assessment of climate change effects is complex. One way to deal with this complexity is by using scenario analysis that takes account of these socio-economic differences. The challenge of developing scenarios is to identify the dimensions along which societies and economies evolve over time in such a way that covers sufficiently different vulnerability patterns. This conceptual effort is critical for the development of informative scenarios. Here, we identify three dimensions on which to build a new set of scenarios to assess climate change effects on human systems. The dimensions we propose take into account the most relevant factors that define the vulnerability of human systems to climate change and their ability to adapt to it.

\section{Introduction}

Since its first report in 1990, the Intergovernmental Panel on Climate Change (IPCC) has aimed to provide information on climate change risks and policy options, to inform decision- and policy-makers. Of particular importance is the assessment of possible climate change impacts, adaptation options, and vulnerabilities (IAV). The 1992 United Nations Convention on Climate Change commits to avoiding 'dangerous' climate change, and as such an IAV assessment is a critical component in determining policy targets for emissions reduction ${ }^{1}$. Information related to impacts are also relevant for designing anticipatory climate change adaptation strategies, and in assessing the financial resources that will be necessary to implement them.

One difficulty in IAV assessment, however, is the fact that future climate change impacts and the desirability of potential adaptation options - depend on many uncertain factors. Some of these factors are environmental, such as the response of the climate system to additional forcing from greenhouse gases (GHG), or the ability of ecosystems to cope with increasing temperatures and modified climate patterns. Climate change impacts and adaptation options will, however, also depend on many socio-economic determinants. The amount of GHG that will be emitted in the future and the ability of affected societies to cope with and adapt to climate change are especially important. These socio-economic determinants of climate change impacts and adaptation options will be driven by future demographic, economic, technological, social, and cultural changes. Any assessment of climate change impacts and adaptation options thus needs to make assumptions about these drivers and their future pathways. To investigate future climate change, a scenario of the pathways of these drivers throughout this century is therefore necessary. 
Considering the wide uncertainties affecting these drivers, using one such scenario only is inappropriate. Climate change vulnerabilities would be underestimated if investigated only using optimistic assumptions, assuming for instance that extreme poverty disappears rapidly in the next decades. Such an underestimation would then lead to inappropriate policy advice on adaptation and mitigation policies. Using only pessimistic scenarios would similarly create a bias in estimates and proposed policies. To make robust decisions, i.e. those that yield acceptable outcomes for a broad range of plausible futures ${ }^{2}$, it is thus necessary to use a set of scenarios that spans the range of possible futures.

Such sets of scenarios have already been developed to investigate climate change and other large-scale environmental and energy issues; see, for example, the Millennium Ecosystem Assessment ${ }^{3}$ or World Energy Outlook$^{4}$. For climate change, the Special Report on Emission Scenarios (SRES) ${ }^{5}$ was produced by the IPCC to provide baseline scenarios for its Third Assessment Report. These scenarios represent "possible and consistent" futures for the world, up to 2100 . They assume - counterfactually - that there are no climate change or climate policies, which is why they are referred to as "baselines."

The SRES scenarios were built by a working group including academic scientists, environmental organizations, industrial scientists, engineers, economists and systems analysts. From different possible pathways of the main drivers of society's evolution, including for example population trends, technological change, and economic growth, etc., they created "storylines" or "narratives", i.e. qualitative descriptions of plausible future world evolutions from which quantitative modelling exercises could then be derived. Depending on the retained assumptions and on the numerical model that was used, the narratives lead to scenarios with different levels of GHG emissions, resulting in different amplitudes and patterns of climate change. They also lead to scenarios with different socio-economic pathways, which can be translated into different climate change vulnerabilities.

As explained in Moss and colleagues ${ }^{6}$, however, the SRES scenarios will be replaced, and new frameworks to develop a new set of scenarios have been suggested ${ }^{7,8}$. Like SRES scenarios, these scenarios will lead to different vulnerabilities and to different GHG emissions. However, in the new approach, climate and socio-economic scenarios are built in parallel, starting from scenarios of future radiative forcings, known as Representative Concentration Pathways, or RCPs. Climate modellers assess the climate response to these forcings, while other modellers build socioeconomic scenarios consistent with these RCPs. Unlike SRES scenarios, some of these new socio-economic scenarios will thus have to include mitigation policies. ${ }^{7,8}$

New scenarios are needed to take into account new data and knowledge on technologies and preferences, and recent economic and demographic evolutions. But most importantly, the SRES scenarios were mainly developed to support mitigation policy analysis, and they have revealed difficult to use by the IAV community. To help the scientific community provide a consistent vision on climate risks and policies, the new scenarios will have to be appropriate both for mitigation and IAV analysis. 
Here, we aim to contribute to the production of these new scenarios by investigating the specific needs of the IAV community. To do so, we first explain how socio-economic scenarios can be used for IAV analysis, and we highlight the limits and strengths of this approach. Then, we review the major vulnerabilities to climate change, and investigate their main socio-economic determinants. Finally, we propose to build a few narratives that cover a broad range of possible evolutions for these determinants, organized along three main dimensions: "homogenous" vs. "heterogeneous"; "poverty and development" vs. "inclusive development"; and "environment-oriented" vs. "environmentally-stressed."

\section{Scenarios for IAV analysis}

Assessing impacts and adaptation options can be done using counterfactual "IAV-baseline" scenarios, i.e. scenarios that assume no climate change (and thus no impacts). A comparison between an IAV-baseline and a scenario including climate change and its impacts informs on the costs and benefits of adaptation actions, and on residual climate change impacts. Unlike SRES scenarios that have been designed mainly to serve as baselines to assess mitigation policies, IAV-baseline scenarios will be used to assess impacts and adaptation policies and may include emission reduction policies.

IAV analyses based on this scenario approach frequently focus on a region or a subsystem (e.g., an ecosystem, an economic sector), and assume that the rest of the world is left unaffected by climate change and follows the evolution described in the baseline scenario. As a consequence, they often do not take into account the interactions of climate change impacts among regions, such as through commodity trade, or subsystems such as when water, energy, and agriculture interact. Moreover, this approach may create inconsistencies as it fails to include how the impacts of climate change modify GHG emissions.

The scenario approach may also be questionable in cases of impacts that are so large that the scenario including climate change differs substantially from the baseline scenario. In that case, the vulnerability determinants (e.g., the number of people with no access to drinking water and sanitation) may be significantly different in the IAVbaseline and in the climate-change scenarios, and baseline vulnerabilities cannot be used to assess climate change impacts. Nevertheless, this methodology makes possible the investigation of individual regions and subsystems independently from each other, a crucial advantage in IAV analysis.

There is another approach used to investigate IAV issues, based on global-scale Integrated Assessment Models (IAMs) such as IMAGE ${ }^{9}$, MiniCAM $^{10,11}$, MERGE ${ }^{12}$, AIM $^{13}$, among others $^{14}$. These models do not share the same limits as scenario-based approaches. In particular, they are able to provide insights on interactions among impacts and to explore possible systemic changes due to climate. They can also include the feedback from impacts to emissions. But IAMs cannot replace detailed local and subsystem IAV analyses, which are too complex for globalscale analysis. As a consequence, scenariobased IAV analyses are likely to remain the standard for the IPCC Fifth Assessment Report.

\section{Challenges in scenario building}

The impacts of climate change will depend on the sensitivity of affected societies and 
economies to changes in climate conditions, and on their ability to adapt to it. The IAVbaseline scenarios thus need to cover the most influential determinants of climate change vulnerability. These determinants can be identified from the IPCC review of the "key vulnerabilities" to climate change ${ }^{15}$ and from the more recent literature that followed. These vulnerabilities can be summarized in four (overlapping) categories.

The first category encompasses climate impacts on agriculture and food security, especially in countries that depend on agricultural production and export for their livelihood and economic sustainability. This topic has been covered in the literature in relation to agriculture ${ }^{16}$, fisheries ${ }^{17}$, and food security and livelihood ${ }^{18}$. The second category includes the health ${ }^{19-21}$ and economic impacts on poor urban and rural communities that lack access to basic services, face multiple stressors $^{22,23}$ and food security issues ${ }^{24}$ and have low adaptive capacity, e.g. lowproductivity food-producing farmers and slum dwellers. The third category of vulnerabilities comprises impacts through extreme events ${ }^{25-30}$ like heat waves, floods and storms, especially but not uniquely in urban areas. The fourth and final category consists of impacts through increased natural resource scarcity (e.g., water scarcity and soil degradation), biodiversity losses, and reduction in ecosystem services. ${ }^{31}$

The welfare impact of these physical vulnerabilities will depend on the adaptive capacity of affected populations, i.e. the ability to moderate potential damages, to take advantage of opportunities, or to cope with the consequences of global warming ${ }^{23,32-34}$. This adaptive capacity depends on financial and technical capacity, access to global financial capital, education and health, institutional capacity and governance, political weight in national and international policy debates, and the support received from other regions or countries (including foreign development aid and more specialized adaptation support).

These categories do not include all factors influencing climate change impacts, especially considering the high level of uncertainty in this domain. Based on current knowledge, however, these categories appear to include the largest vulnerabilities, and we argue that IAV-baseline scenarios ought to cover their drivers and the uncertainties that surround them.

\section{Proposed dimensions of the narratives}

One way of constructing narratives for IAVbaselines could be to create a very large number of scenarios that cover all identified uncertainties, and to assess climate change impacts and adaptation options in each of the scenarios. Then, it would be possible to select the few scenarios that are especially relevant for any particular decision that needs to be made: the most relevant scenarios may not be the same for analysing climate impacts and adaptation options in the agriculture sector or in the energy sector. This approach - labelled "scenario discovery" by Groves and Lempert $^{35}$ - is however difficult to apply to IAV analyses, considering the difficulty and resources involved in any impact or adaptation study. It appears unrealistic to investigate all climate impacts and adaptation options in more than a few scenarios.

As an alternative, we propose to follow the classical approach used for the SRES scenarios, and to build a small set of qualitative narratives organized along a few dimensions that summarize what we expect to be the main determinant of the key vulnerabilities to climate change. Importantly, these dimensions are not the driving forces 
behind the changes, but the results of a combination of driving forces (e.g., demographic changes, technological change).

To cover as extensively as possible the potential futures of these determinants, and thus the possible futures of climate change vulnerabilities, we propose to build the narratives from a combination of three choices, one for each of the three following dimensions.

The first of our proposed dimensions considers the possibility of a "homogeneous" world vs. a "heterogeneous" world. In a more homogeneous world, the economic and spatial structure of developing countries converges rapidly toward the economic and spatial structure of industrialized countries. For instance, the share of agriculture in developing-world economies decreases in terms of GDP and exports. Also, urbanization rates converge around developed-country standards; and available technologies are similar in industrialized and developing countries. Conversely, in a more heterogeneous world, developing-country economies remain for an extended period of time based on agriculture, raw-material extraction, and tourism. These countries remain largely rural. In such a world, developing countries are more dependent on rich countries for high-technology goods and can balance their imports only thanks to lowvalue-added goods and services. In contrast with the globalization dimension used in SRES scenarios, this dimension is not mainly about trade and openness, even though a more homogenous world has more international trade than more heterogeneous ones. This dimension is important for IAV analysis for two main reasons. First, depending on how developing countries and their economic structure evolve, the nature of their vulnerabilities will be different. Economies that remain rural and rely heavily on agriculture will have different vulnerabilities than countries that become urban and shift toward industries and services. Agriculture in developing countries is likely one of the sectors most negatively affected by climate chang $\mathrm{e}^{16}$. In a more homogenous world, these countries would be less vulnerable because agriculture becomes less important in their economy. They would also be at reduced risks of food insecurity because of better access to world food markets thanks to alternative nonagricultural exports ${ }^{36}$. However, their urban population may be more vulnerable to natural disasters such as floods, and to network disruptions affecting electricity distribution or transport networks.

Our second proposed dimension distinguishes between an "inclusive development" in which extreme poverty disappears rapidly vs. a "growth and poverty" development with a significant share of people remaining below the poverty line. This dimension represents inequalities within countries and regions. In a more inclusive world, the poorest communities have a voice in political choices, governance takes into account poverty reduction as an important policy goal, and the share of people in extreme poverty is rapidly reduced. Almost everybody gets access to basic services, such as health services, education, energy and transport, drinking water and sanitation, financial services, secured land tenure and decent housing, risk management practices (e.g., buying insurance or building dams). In a more "poverty and development" oriented world, a fraction of poor-country population is excluded from these services (e.g., urban poor in informal settlements). Development is uneven within countries, with some regions lagging behind average development (e.g., inland vs. coastal 
areas), creating large pockets of extreme poverty. This dimension is partly independent of the previous one, because extreme poverty may either disappear or increase, regardless of economic structure and aggregate economic growth. This dimension can also include differences in terms of governance efficiency, e.g. in the ability to efficiently deal with conflicts over resources. It is important for IAV analysis to take into account this dimension because poor communities are considered the most vulnerable to climate change $^{37}$. They are more exposed to environmental conditions and rely more heavily on unmediated environmental resources (e.g., their access to water is not mediated by infrastructure). They also have to cope with multiple stressors ${ }^{23}$ and have less capacity to adapt, because of lower financial capacity, education and health, institutional capacity, or political weight ${ }^{32}$.

The last dimension in our proposal opposes an "environment-oriented" world vs. an "environmentally-stressed" world. In an environment-oriented world, policies, technologies and lifestyles lead to an efficient use of natural resources and reduce environmental stresses. In an environmentallystressed world, water-use is inefficient, energy and mobility demands are growing. Soil depletion and degradation are accelerated and reduce agriculture productivity and increase natural risks (e.g., floods). Biodiversity losses are large and ecosystem services are threatened. In this world, the unsustainable use of natural resources is creating environmental stresses, so that climate change affects already vulnerable environments. This dimension is largely independent of the previous ones, since economic development and poverty reduction may be done - temporarily - with or without efficient use of natural resources. This dimension is also independent from the implementation of climate policies. Indeed, many environmental problems improve spontaneously as country development exceeds a certain level (e.g., city air pollution), while GHG emissions may keep increasing with development, at least in some countries (the literature on the Environmental Kuznets Curve explores these issues ${ }^{38}$ ). It matters for IAV analysis because ecosystems ability to cope with climate change depends on the other stresses they have to cope with ${ }^{39}$, and because additional resource scarcity from climate change can have different consequences depending on how they are managed. For instance, reduced rainfall has larger economic consequences if existing resources are already stretched by inappropriate agriculture production and if ground water is not usable because of pollution or salinization ${ }^{40}$.

Many other factors will be important in world evolutions and will influence vulnerability. For instance, other factors such as the consequences of the 2008 financial crisis may be more important for near-term vulnerability, e.g., up to 2030. Also, since climate change impacts and adaptation options are very context-specific and require local studies, global scenarios will need to be downscaled into local scenarios ${ }^{41}$. At a local scale, some factors that are secondary at the global scale may become dominant. But at the global scale and over the long term, i.e. up to 2100 , the three dimensions we propose in this paper appear to us as the main drivers of climate change vulnerability.

\section{One way forward}

To build narratives, two possibilities can be selected for each dimension, leading to eight narratives - and eight IAV-baseline scenarios - that can be located along our three axes (homogeneous vs. heterogeneous; inclusive 
vs. poverty and development; environmentoriented vs. environmentally-stressed; Fig 1). These dimensions provide thus a mapping of future possible worlds. In addition to these dimensions, it has been proposed that IAVbaseline scenarios may include mitigation policies, such that GHG emissions follow one of the $\mathrm{RCPs}^{7,8}$. Comparing climate change impacts and adaptation options with different mitigation policies (leading to different RCPs) in the same narratives would inform on the benefits from mitigation.

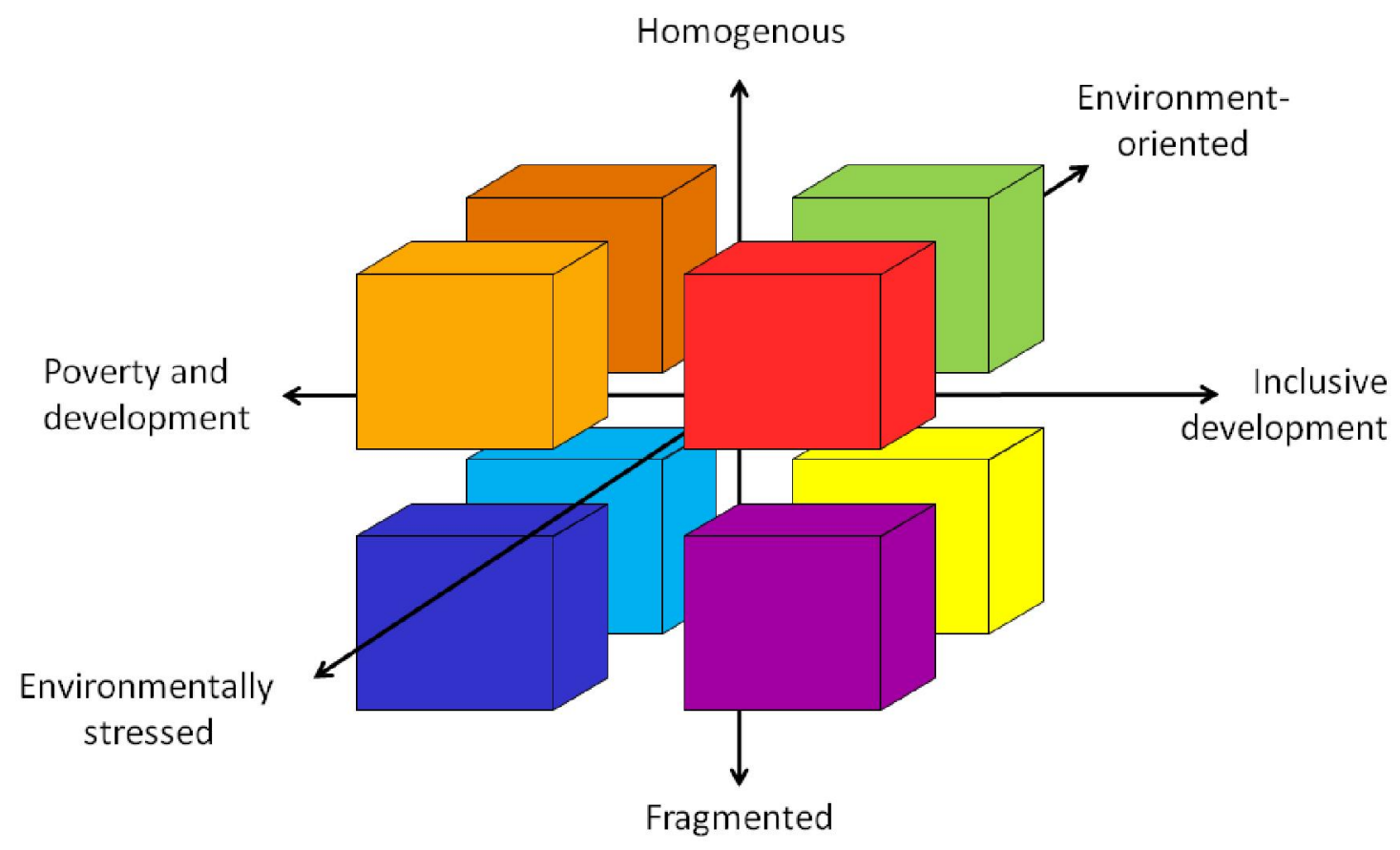

Figure 1: Narrative representation with three dimensions.

The possibilities for each dimension need to be contrasted enough to lead to narratives that are sufficiently distinct in their vulnerability patterns. The quantification of these narratives remains to be done, and additional work is needed to build scenarios. In particular, it will be necessary to decide how contrasted the narratives should be (e.g., what is the difference in urbanization rate between the homogenous and heterogeneous worlds?), and to build them in a way that ensures their internal consistency. Such quantification may show that the eight narratives are not equally realistic and consistent. A careful quantified analysis may even lead us to discard some of the combinations of drivers displayed in Figure 1. But before the scientific community starts to run models and invest in scenario building, a debate on the most appropriate dimensions of the analysis needs to be held. We hope this proposal can help to initiate and contribute to this important debate.

\section{Acknowledgments}

The authors want to thank Patrice Dumas, Céline Guivarch, Brian O'Neill, Philippe Quirion, Philippe Roudier, Julie Rozenberg, Henri Waisman and two anonymous referees for their useful comments on a previous version of this paper. We also want to thank the AUGUR project, funded by the EU 7th Research Framework, for their financial support. 
Author's copy.

Published in Nature Climate Change 1, n. 3 (june 2011): 151-155. | DOI: 10.1038/NCLIMATE1135

\section{References}

1. Schneider, S. What is « dangerous » climate change? Nature 17-19 (2001).

2. Schwartz, P. The art of the long view: planning for the future in an uncertain world. (Wiley New York, NY: 1998).

The rationale behind the use of long term scenarios for robust decision-making.

3. Millennium Ecosystem Assessment Ecosystems and human well-being. 5, (Island Press: 2005).

4. International Energy Agency World energy outlook. (OECD/IEA,: Paris, France, 2009).

5. Nakicenovic, N. et al. Special report on emissions scenarios: a special report of Working Group III of the Intergovernmental Panel on Climate Change. (Pacific Northwest National Laboratory, Richland, WA (US), Environmental Molecular Sciences Laboratory (US): 2000).

6. Moss, R.H. et al. The next generation of scenarios for climate change research and assessment. Nature 463, 747-756 (2010).

An up-to-date review of the history of climaterelated scenarios and a presentation of the scenario process behind the creation of Representative Concentration Pathways (RCPs), which will be used for the next IPCC assessment.

7. Kriegler, E. et al. Socio-economic Scenario Development for Climate Change Analysis. CIRED Working Papers (2010). A proposed framework for the new generation of IPCC socio-economic scenarios, consistent with the RCPs.

8. van Vuuren, D.P. et al. Developing new scenarios as a thread for future climate research. (Working paper: 2010).

A proposed framework for the new generation of IPCC socio-economic scenarios, consistent with the RCPs.

9. Bouwman, A.F., Kram, T. \& Goldewijk, K.K. Integrated modelling of global environmental change: an overview of Image 2.4. (Netherlands Environmental Assessment Agency: 2006).

10. Edmonds, J.A., Clarke, J., Dooley, J., Kim, S.H. \& Smith, S.J. Modeling greenhouse gas energy technology responses to climate change. Energy 29, 1529-1536 (2004).

11. Wise, M. et al. Implications of

Limiting $\mathrm{CO} 2$ Concentrations for Land Use and Energy. Science 324, 1183-1186 (2009). 12. Manne, A.S. \& Richels, R.G. Merge: An Integrated Assessment Model for Global Climate Change. Energy and Environment 175-189 (2005).

13. Fujino, J., Nair, R., Kainuma, M., Masui, T. \& Matsuoka, Y. Multi-gas mitigation analysis on stabilization scenarios using AIM global model. The Energy Journal 343-354 (2006).

14. Weyant, J.P., De la Chesnaye, F.C. \& Blanford, G. Overview of EMF- 21: Multigas Mitigation and Climate Change. Energy Journal 22, (2006).

15. Parry, M.L. Climate Change 2007: impacts, adaptation and vulnerability: contribution of Working Group II to the fourth assessment report of the Intergovernmental Panel on Climate Change. (Cambridge Univ Pr: 2007).

16. Lobell, D.B. et al. Prioritizing Climate Change Adaptation Needs for Food Security in 2030. Science 319, 607-610 (2008).

17. Allison, E.H. et al. Vulnerability of national economies to the impacts of climate change on fisheries. Fish and Fisheries 10, 173-196 (2009).

18. Conway, D., Allison, E., Felstead, R. \& Goulden, M. Rainfall variability in East Africa: implications for natural resources management and livelihoods. Philosophical Transactions of the Royal Society A: Mathematical, Physical and Engineering Sciences 363, 49-54 (2005).

19. Patz, J.A., Campbell-Lendrum, D., Holloway, T. \& Foley, J.A. Impact of regional climate change on human health. Nature 438, 310-317 (2005).

20. Ebi, K.L. \& Semenza, J.C.

Community-Based Adaptation to the Health Impacts of Climate Change. American Journal of Preventive Medicine 35, 501-507 (2008).

21. Costello, A. et al. Managing the health effects of climate change. The Lancet 373, 1693-1733 (2009).

22. Revi, A. Climate change risk: an adaptation and mitigation agenda for Indian 
Author's copy.

Published in Nature Climate Change 1, n. 3 (june 2011): 151-155. | DOI: 10.1038/NCLIMATE1135

cities. Environment and Urbanization 20, 207229 (2008).

23. O'Brien, K.L. \& Leichenko, R.M. Double exposure: assessing the impacts of climate change within the context of economic globalization. Global Environmental Change 10, 221-232 (2000).

A presentation of the importance of interactions between multiple vulnerabilities, and especially those linked to globalization and climate change.

24. Gregory, P.J., Ingram, J.S.I. \&

Brklacich, M. Climate change and food security. Philosophical Transactions of the Royal Society B: Biological Sciences 360, 2139 (2005).

25. Helmer, M. \& Hilhorst, D. Natural disasters and climate change. Disasters 30, 1-4 (2006).

26. Van Aalst, M.K. The impacts of climate change on the risk of natural disasters. Disasters 30, 5-18 (2006).

27. Pelling, M. Natural disasters and development in a globalizing world.

(Routledge: London; New York, 2003).

28. Rosenzweig, C., Solecki, W., Hammer, S.A. \& Mehrotra, S. Cities lead the way in climate-change action. Nature 467, 909-911 (2010).

29. Hallegatte, S. \& Corfee-Morlot, J. Understanding climate change impacts, vulnerability and adaptation at city scale: an introduction. Climatic Change 104, 1-12 (2010).

30. Hardoy, J. \& Pandiella, G. Urban poverty and vulnerability to climate change in Latin America. Environment and Urbanization 21, 203-224 (2009).

31. Hoegh-Guldberg, O. et al. Coral Reefs Under Rapid Climate Change and Ocean Acidification. Science 318, 1737-1742 (2007). 32. Yohe, G. \& Tol, R.S.J. Indicators for social and economic coping capacity--moving toward a working definition of adaptive capacity. Global Environmental Change 12, 25-40 (2002).

33. Bennett, E.M. \& Balvanera, P. The future of production systems in a globalized world. Frontiers in Ecology and the Environment 5, 191-198 (2007).
34. Young, O.R. et al. The globalization of socio-ecological systems: An agenda for scientific research. Global Environmental Change 16, 304-316 (2006).

35. Groves, D. \& Lempert, R. A new analytic method for finding policy-relevant scenarios. Global Environmental Change 17, 73-85 (2007).

36. Chen, R.S. \& Kates, R.W. World food security: prospects and trends. Food Policy 19, 192-208 (1994).

37. Smit, B. \& Wandel, J. Adaptation, adaptive capacity and vulnerability. Global Environmental Change 16, 282-292 (2006). 38. Dasgupta, S., Laplante, B., Wang, H. $\&$ Wheeler, D. Confronting the Environmental Kuznets Curve. The Journal of Economic Perspectives 16, 147-168 (2002).

39. Noble, D. Climate Change. Ecosystems and human well-being 5, (2005).

40. Arnell, N. Climate change and global water resources: SRES emissions and socioeconomic scenarios. Global Environmental Change 14, 31-52 (2004).

41. van Vuuren, D.P., Smith, S.J. \& Riahi, K. Downscaling socioeconomic and emissions scenarios for global environmental change research: a review. WIREs Clim Chang 1, 393404 (2010). 